\title{
GLOMERULOSCLEROSIS IN TRANSGENIC RABBITS WITH UBIQUITOUS VENUS PROTEIN EXPRESSION
}

\author{
Nándor LIPTÁK*, Orsolya Ivett HofFMANN, Gabriella SKODA, Elen GócZA, \\ Andrea KEREKES, Zsuzsanna BöSZE and László HIRIPI \\ Animal Biotechnology Department, NARIC Agricultural Biotechnology Institute, \\ Szent-Györgyi A. u. 4, H-2100 Gödöllö, Hungary
}

(Received 23 May 2017; accepted 16 April 2018)

\begin{abstract}
Focal segmental glomerulosclerosis (FSGS) is a potential cause of nephrotic syndrome both in humans and pet mammals. Glomerulopathy was reported earlier in green fluorescent protein (GFP) transgenic (TG) mice, but glomerulosclerosis has not been examined in GFP TG rabbits so far. In the present study, the potential manifestation of FSGS was investigated in both Venus TG rabbits generated by Sleeping Beauty (SB) transposition and age-matched control New Zealand White (NZW) rabbits. Venus protein fluorescence was detected by confocal microscopy and quantified by microplate reader. Urinalysis, haematology, serum biochemistry and renal histology were performed to assess the signs of FSGS. Higher levels of Venus fluorescence were determined in renal cortex samples than in the myocardium by both methods. Urinalysis revealed proteinuria in Venus heterozygote TG bucks, while Venus homozygote TG bucks developed microscopic haematuria. Supporting the urinalysis data, the histological findings of FSGS (glomerulomegaly and sclerotic glomeruli) were observed in renal cortex sections of Venus TG rabbits. Taken together, Venus TG bucks were diagnosed with FSGS; thus, this type of glomerulopathy could be a common disease in TG animals overexpressing GFP.
\end{abstract}

Key words: Focal segmental glomerulosclerosis, transgenic rabbits, urinalysis

Focal segmental glomerulosclerosis (FSGS) is a chronic renal disease and the most frequent glomerular disorder which may cause end-stage renal disease in humans (D'Agati et al., 2011). The main signs of FSGS are marked proteinuria and podocyte injury. FSGS was first identified in 1970 as a separate histopathological entity (Churg et al., 1970). FSGS can be primary (the initial cause is not known) or secondary (e.g. obesity- or drug-induced, virus infectionassociated, etc). Approximately $80 \%$ of FSGS cases are primary with poor sensitivity to steroid treatment (D’Agati et al., 2011). Clinical investigations demon-

*Corresponding author; E-mail: liptak.nandor@abc.naik.hu; Phone: 0036 (28) 526-253; Fax: 0036 (28) 526-151 
strated that men have a worse outcome than women in the severity and progression of FSGS; this male predominance was also observed in laboratory animals (Kummer et al., 2012). For a better understanding of the underlying mechanism, transgenic (TG) rodent models for FSGS were established (Hocher et al., 1997; Michaud et al., 2003). Green fluorescent protein (GFP) TG mice also had renal abnormalities which led to glomerulosclerosis (Guo et al., 2007). In another report, more severe proteinuria and higher numbers of sclerotic glomeruli were observed in a GFP TG mouse strain after doxorubicin treatment compared with non-TG mice (Takagi-Akiba et al., 2012).

FSGS may also occur in pet mammals, e.g. dogs, cats and rabbits (Hinton, 1981; Khan and Khan, 2015). In experiments involving surgical methods, rabbits are a better choice than mice due to their larger organs; thus, the development and characterisation of TG rabbit FSGS models could be useful in veterinary medicine.

Here we report the assessment of FSGS in TG rabbits generated by Sleeping Beauty (SB) transposition expressing the Venus protein (Katter et al., 2013). The Venus transgene integrated into the rabbit genome in one monomeric copy at chromosome 8. The genomic region of the Venus TG construct has been updated recently, and the transgene was located in the intron 12-13 of the diaphanous related formin 3 gene (DIAPH3, Ensembl gene ID: ENSOCUG00000001719). Besides looking for the signs of FSGS (sclerotic glomeruli, proteinuria, haematuria), the possible presence of underlying disorders (obesity, dilated cardiomyopathy, polycythaemia vera) was also examined. Heart-specific GFP expression caused dilated cardiomyopathy in TG mice (Huang et al., 2000), which cardiac disease may be associated with FSGS (Adedoyin et al., 2004).

Using Venus TG rabbits bred and tested for homozygosity, we could test the hypothesis whether higher fluorophore expression causes more severe signs in Venus homozygote TG compared to heterozygote TG rabbits. Venus protein is a yellow shifted variant of the GFP (Shimomura et al., 1962). Its expression is driven by the constitutive cytomegalovirus enhancer and chicken beta actin promoter (CAGGS). Transgene silencing was not observed throughout four generations of the TG line. As in Venus TG pigs (Garrels et al., 2011), reduced litter size or adverse effects of Venus expression on fecundity were not observed in TG rabbits (Liptak et al., 2017). In our previous study, robust expression of Venus protein in all organs was demonstrated in a male founder by fluorescence microscopy (Katter et al., 2013).

Although there are published observations about glomerulosclerosis in enhanced green fluorescent protein (EGFP) TG mice, the possible manifestation of FSGS in CAGGS-GFP TG rabbits (Takahashi et al., 2007) or in other EGFP TG non-mouse species has not been examined yet. The aim of the present study was to clarify whether TG rabbits with ubiquitous fluorophore expression had a glomerular disorder similar to that reported previously in EGFP TG mice. 


\section{Materials and methods}

\section{Ethics statement}

All experiments were approved by the Animal Care and Ethics Committee of the NARIC Agricultural Biotechnology Institute and the government office of Pest County (permission numbers: PEI/001/329-4/2013 and PEI/01/857-3/2015). The experiments complied with the Hungarian Code of Practice for the Care and Use of Animals for Scientific Purposes, including the conditions for animal welfare and handling prior to slaughter.

\section{Animals}

Venus TG and wild-type NZW bucks (age: 4-5 months) were used for investigating the main signs of FSGS. Besides one control and two Venus TG heterozygote bucks, an additional 8-month-old Venus homozygote TG buck was also tested for signs of obesity and dilated cardiomyopathy. Venus homozygote TG rabbits were crossed to obtain homozygote TG; while wild-type $O$ X Venus heterozygote TG $\widehat{\supset}$ mating resulted in Venus heterozygote TG and wild-type offspring. In line with our previous observations, Venus TG newborns exhibited macroscopic Venus specific fluorescence under UV light illumination, while non-TG rabbits remained Venus negative (Katter et al., 2013). Additionally, all offspring were tested for the presence of the Venus transgene using standard polymerase chain reaction (PCR). The animals were kept under a standard lightdark cycle in the same animal house (lights on between 07:00 a.m. and 07:00 p.m.) at $18 \pm 3{ }^{\circ} \mathrm{C}$ with food and water available ad libitum and caged separately.

\section{Blood sample collection and analysis}

Peripheral blood samples were obtained into K3-EDTA containing tubes (Microvette, Sarstedt, Germany) from the ear arteries of rabbits (Jenkins, 2008). Blood sampling was performed between 01:00 and 02:00 p.m. to avoid fluctuations caused by circadian rhythm. Parameters were counted by an Abacus Junior Vet5 haematology analyzer. Differential leukocyte counts were evaluated by counting 100 cells in blood smears stained with Diff-Quick.

Serum biochemistry (creatinine, albumin, cholesterol and triglycerides, Vacutainer serum tubes) was also performed in four rabbits (one wild type, two Venus heterozygote TG and one Venus homozygote TG).

\section{Urinalysis}

After blood sample collection, rabbit urine samples $(2-5 \mathrm{ml})$ were obtained with gentle bladder expression under anaesthesia (Melillo, 2007) with the combination of Ketamidor (Richter Pharma AG, Hungary) and Xylazine (CP- 
LIPTÁK et al.

Pharma, Germany, IV). Total protein (TP, g/L) and creatinine (Crea, g/L) concentrations in the urine supernatant; the number of leukocytes and red blood cells (RBCs) per high power field (HPF) in the sediment were measured as the parameters of proteinuria and haematuria. The TP $(\mathrm{g} / \mathrm{L})$ concentration of urine supernatants $(20 \mu \mathrm{l}$ from each sample) were estimated by the pyrogallol red-molybdate method with a clinical chemistry analyzer (Olympus AU400, Olympus Diagnostica, Germany). The total protein ultrasensitive kit (Diagnosticum Inc., Hungary) was used for the colorimetric measurements. TP/Crea ratio under 0.6 (Melillo, 2007), TP (g/L) under $1 \mathrm{~g} / \mathrm{L}$ and maximum 3 RBCs in the sediment (Jenkins, 2008) were accepted as normal. TP concentrations between $1-3 \mathrm{~g} / \mathrm{L}$ were defined as mild, and those above $3 \mathrm{~g} / \mathrm{L}$ as severe proteinuria (Matsuo et al., 1987). The supernatants of urine samples were also tested for the presence of glucose, ketone, haemoglobin and protein.

\section{Detection and measurement of Venus expression in heart and kidney samples}

Venus expression in the glomeruli and myocardium were visualised by confocal microscopy. Nuclei were stained with propidium iodide (Molecular Probes, Invitrogen, UK) and mounted with FluorSave reagent (Merck Millipore, USA). The images of the sections were obtained with a Leica TCS SP8 confocal microscope equipped with PMT (gain $550 \mathrm{~V}$ ) detector. The detection range of the Venus channel was $510-570 \mathrm{~nm}$, while the propidium iodide staining was recorded at 580-700 $\mathrm{nm}$.

Venus fluorescence was quantified by a microplate reader (Hidex Cameleon 2000, Finland). Tissue samples were prepared according to the manufacturer's instructions (GFP Quantitation kit, Cell Biolabs, Inc., USA). Same-amount tissue samples were homogenised with $500 \mu 11 \times$ lysis buffer, then the tissue lysates were centrifuged for $5 \mathrm{~min}$ at $13,000 \mathrm{rpm}$. The supernatants $(100 \mu \mathrm{l})$ were transferred to a 96-well plate and their fluorescence was recorded at 485/535 nm. Each sample was assayed in duplicate.

The Venus protein concentrations of the tissue samples were calculated according to following equation:

$\left(\right.$ Fluo $_{\text {sample }} /$ Fluo $\left._{\text {GFP.standard }}\right) \times \mathrm{C}_{\text {GFP.standard }}=\mathrm{C}_{\text {sample }}$

where Fluo is the fluorescence and $\mathrm{C}$ is the concentration.

\section{Histology and gross pathology examination}

After urine and blood sampling, the rabbits were sacrificed; the heart and kidneys were removed, washed in PBS, and then fixed in $4 \%(\mathrm{w} / \mathrm{v})$ PFA at $4{ }^{\circ} \mathrm{C}$ for $24 \mathrm{~h}$. Tissue samples for histology were replaced in the cryoprotective $30 \%$ $(\mathrm{w} / \mathrm{v})$ sucrose-PBS solution at $4{ }^{\circ} \mathrm{C}$ for $24 \mathrm{~h}$. The samples were embedded into cryomedium before cryosectioning (Cryomatrix, Thermo Scientific, USA) and cut into $10 \mu \mathrm{m}$ thick sections on a cryostat (Microm, Germany) for confocal imaging. 
Haematoxylin and eosin (HE) staining was performed on paraffinembedded renal cortex and myocardium sections (Haemalum and eosin Y solution, Carl Roth GmbH, Germany). Renal cortex sections were also stained with Periodic acid-Schiff (PAS) solutions for further evaluation of glomerular morphology (Periodic acid solution 1\% and Schiff's reagent, Carl Roth GmbH, Germany). Fifty glomeruli from the entire renal cortex of each rabbit were examined for glomerulosclerosis. Glomeruli were taken as sclerotic if the mesangial expansion was more than $30 \%$ in the glomerular area (Kimura et al., 1991). After staining, sections were mounted with DPX (Fluka, Germany). Myocardium sections were studied for the presence of changes indicative of dilated cardiomyopathy (vacuolisation, granulation, necrosis and interstitial fibrosis (Gava et al., 2013). Tissue sections of each rabbit were analysed by light microscopy [Olympus BH2 (BH4), Germany] and photographed with a smartphone (Samsung Electronics, South Korea).

In the case of four rabbits (one wild type, two Venus heterozygote TG and one Venus homozygote TG), gross examination of the heart and kidneys was also performed. After fixation, kidneys and hearts were halved and the gross morphology was analysed with the naked eye. Heart and kidney mass/body mass ratios $(\mathrm{g} / \mathrm{kg})$ were also calculated.

\section{Statistical analysis}

Statistical analyses were performed by one-way ANOVA followed by Tukey post-hoc test using PSPP Statistical Analysis Software 0.8.4. A probability value of $\mathrm{P}<0.05$ was considered statistically significant.

\section{Results}

\section{Complete blood count and serum biochemistry}

Complete blood counts were within the normal reference ranges in all groups (data not shown). Serum cholesterol levels were slightly elevated in the Venus TG bucks (heterozygote: 0.9 and $1.6 \mathrm{mmol} / \mathrm{L}$, respectively; homozygote: $1.7 \mathrm{mmol} / \mathrm{L})$ compared to the control buck $(0.7 \mathrm{mmol} / \mathrm{L})$, but serum parameters of all rabbits were within the normal reference ranges.

\section{Urinalysis}

The urine supernatants of all rabbits were negative for glucose, ketone and haemoglobin with normal $\mathrm{pH}$. The supernatants of control bucks were also negative for protein, while the samples of 6 Venus TG bucks (4 heterozygote, 2 homozygote) were found to be positive for protein by the sulphosalicylic acid test. $\mathrm{TP} /$ Crea ratio in Venus TG heterozygote bucks was significantly higher com- 
pared with the control bucks (see statistics in Table 1). The urine sediment of Venus heterozygote TG and control rabbits contained RBCs and leukocytes within normal ranges. Two out of five Venus homozygote TG bucks developed microscopic haematuria (15 and $30 \mathrm{RBCs} / \mathrm{HPF}$, respectively).

Table 1

Proteinuria and microscopic haematuria in Venus transgenic (TG) bucks

\begin{tabular}{lccc}
\hline Groups & $\begin{array}{c}\text { Non-TG } \\
\text { control } \\
(\mathrm{n}=6)\end{array}$ & $\begin{array}{c}\text { Venus TG } \\
\text { heterozygote } \\
(\mathrm{n}=6)\end{array}$ & $\begin{array}{c}\text { Venus TG } \\
\text { homozygote } \\
(\mathrm{n}=5)\end{array}$ \\
\hline Proteinuria (sulphosalicylic acid test) & not detected & in 4 bucks & in 2 bucks \\
Microscopic haematuria & not detected & not detected & in 2 bucks \\
TP (g/L) & $0.38 \pm 0.51$ & $1.88 \pm 1.58$ & $0.45 \pm 0.29$ \\
TP/Crea ratio & $0.29 \pm 0.23$ & $1.79 \pm 1.61^{*}$ & $0.43 \pm 0.34$ \\
\hline
\end{tabular}

TP: total protein; Crea: creatinine. The mean value of TP/Crea in Venus TG heterozygote bucks was significantly higher compared to controls. TP $(\mathrm{g} / \mathrm{L})$ ratio was also elevated in Venus TG heterozygote bucks, but not significantly compared with the control group $(\mathrm{P}=0.052)$. Data are presented as mean $\pm \mathrm{SD}$. Asterisk denotes significant differences: $\mathrm{TP} /$ Crea ratio: ${ }^{*} \mathrm{~F}_{(2.14)}=4.12, \mathrm{P}=$ 0.049 compared with control bucks, respectively

\section{Venus protein expression in histological sections and tissue samples}

The fluorophore expression in the renal cortex and myocardium of Venus TG and control rabbits was visualised by confocal microscopy (Fig 1a-f). Venus homozygote TG bucks showed stronger Venus protein expression in both tissues than Venus heterozygote TG bucks. Venus fluorescence was stronger in the renal cortex (Fig 1b-c) than in the myocardium (Fig 1e-f). The sections of control rabbits were Venus negative (Fig. 1a, d).

Higher Venus protein concentration was determined in tissue lysates extracted from renal cortex samples than in those from the myocardium. The tissue lysates of Venus homozygote TG rabbits displayed higher levels of fluorescence than those of Venus heterozygote TG rabbits (see data in Table 2).

\section{Histology and gross assessment}

Contrary to control rabbits, which showed normal glomerular histology (Fig. 2a, d), Venus TG bucks of both genotypes had sclerotic glomeruli (Fig. 2e-f) and their sclerotic glomeruli/50 glomeruli ratio was significantly higher than that of the control rabbits (see statistics in Table 3). Glomerulomegaly was observed for 4-5 glomeruli in the sections of Venus TG rabbits (Fig. 2b, c) (4 heterozygote, 4 homozygote), but not in sections of wild-type rabbits.

Intracytoplasmic vacuolisation was detected in the myocardium sections of a Venus homozygote TG buck, but other histological findings of dilated cardi- 
omyopathy (granulation, necrosis and interstitial fibrosis) were not observed in any of the Venus TG and non-TG rabbits (sections not shown).

Venus TG (2 Venus heterozygote TG and 1 Venus homozygote TG) bucks (Fig. 3b-c) had slightly dilated left ventricle, but their ventricular walls were not thinner compared to the control buck (Fig. 3a). The fat deposits were larger in the renal pelvis and renal medulla of Venus TG rabbits than in the control (Fig. $3 d-f)$.

Table 2

Quantification of Venus protein concentration in tissue lysates

\begin{tabular}{|c|c|c|c|c|c|c|}
\hline \multirow{2}{*}{$\begin{array}{l}\text { Animals } \\
\text { Tissue } \\
\text { lysates }\end{array}$} & \multicolumn{2}{|c|}{$\begin{array}{l}\text { Non-TG control } \\
\qquad(\mathrm{n}=2)\end{array}$} & \multicolumn{2}{|c|}{$\begin{array}{l}\text { Venus heterozygote TG } \\
\qquad(\mathrm{n}=2)\end{array}$} & \multicolumn{2}{|c|}{$\begin{array}{l}\text { Venus homozygote TG } \\
\qquad(\mathrm{n}=2)\end{array}$} \\
\hline & $\begin{array}{l}\text { Renal } \\
\text { cortex }\end{array}$ & Myocardium & $\begin{array}{l}\text { Renal } \\
\text { cortex }\end{array}$ & Myocardium & $\begin{array}{l}\text { Renal } \\
\text { cortex }\end{array}$ & Myocardium \\
\hline $\begin{array}{l}\text { Venus } \\
\text { protein } \\
(\mu \mathrm{g} / \mathrm{ml})\end{array}$ & $\begin{array}{c}0.52 \pm \\
0.02\end{array}$ & $\begin{array}{l}0.23 \pm \\
0.02\end{array}$ & $\begin{array}{c}85.79 \pm \\
2.07\end{array}$ & $\begin{array}{c}28.56 \pm \\
2.75\end{array}$ & $\begin{array}{c}137.34 \pm \\
17.74\end{array}$ & $\begin{array}{c}34.83 \pm \\
2.74\end{array}$ \\
\hline
\end{tabular}

Higher Venus protein concentration was observed in tissue samples of Venus homozygote TG bucks than in Venus heterozygote TG bucks. Renal cortex samples had greater Venus fluorescence than the myocardium in both Venus heterozygote TG and homozygote TG bucks. Only autofluorescence was detected in the lysates of control bucks (mean $\pm \mathrm{SD}$ )

\section{Discussion}

TG rabbits are laboratory animals widely used for modelling human diseases, but experimental data about glomerular disorders in GFP TG rabbits have not been published yet. Glomerulopathy was observed in $\beta$-actin EGFP TG mice (Guo et al., 2007). Only TG mice with the highest EGFP expression in their glomeruli developed glomerulosclerosis; other TG strains with lower EGFP expression displayed normal renal morphology. Unfortunately, the C57BL/6TG(CAG-EGFP)1Osb/J homozygote line was not examined due to the premature death of these mice (Guo et al., 2007); thus, the urinalysis data and renal histology of Venus homozygote TG rabbits and EGFP homozygote TG mice could not be compared.

In the current study, the main signs of FSGS were studied in both Venus heterozygote and homozygote TG rabbits.

The complete blood count gives important information about the general health status of rabbits. In a few cases, FSGS in humans may be associated with polycythaemia vera, which is a myeloproliferative disease with overproduction of RBCs, leukocytes and platelets (Okuyama et al., 2007). In our experiments, the complete blood counts of both Venus TG and control rabbits were normal, so polycythaemia vera as a potential basis of FSGS in Venus TG rabbits could be ruled out. 

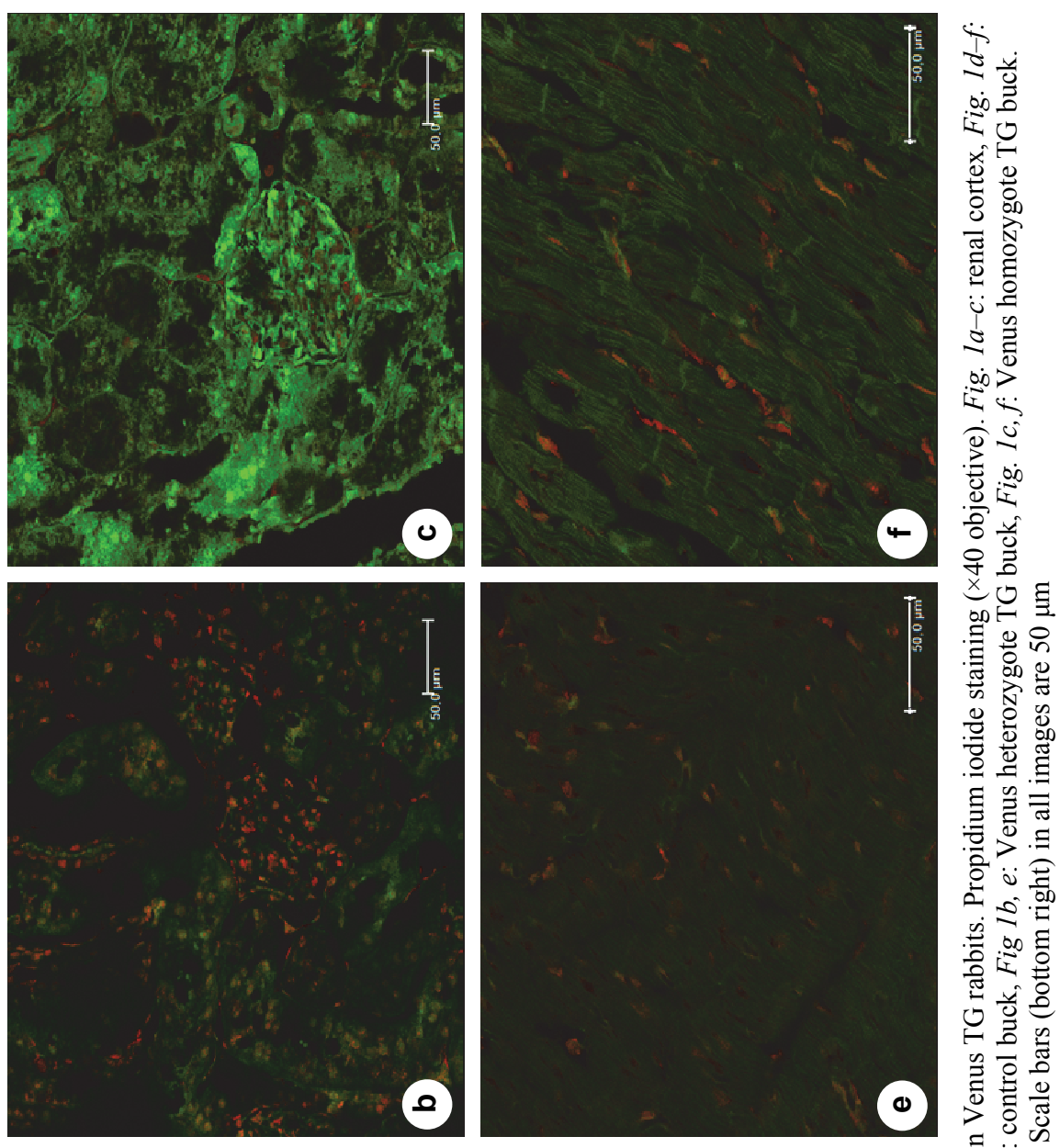

으

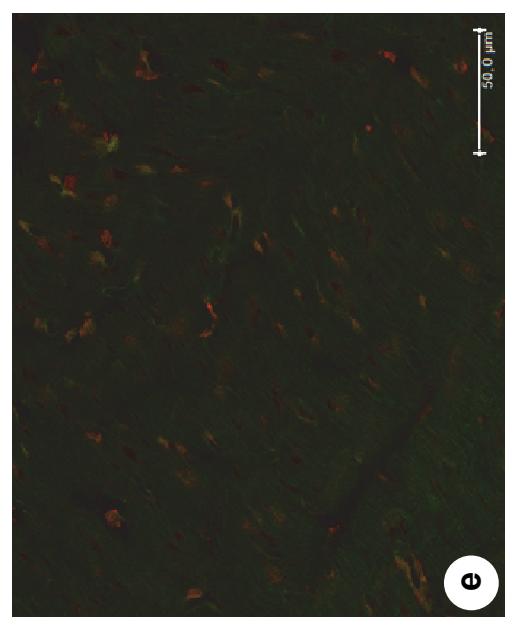

讨

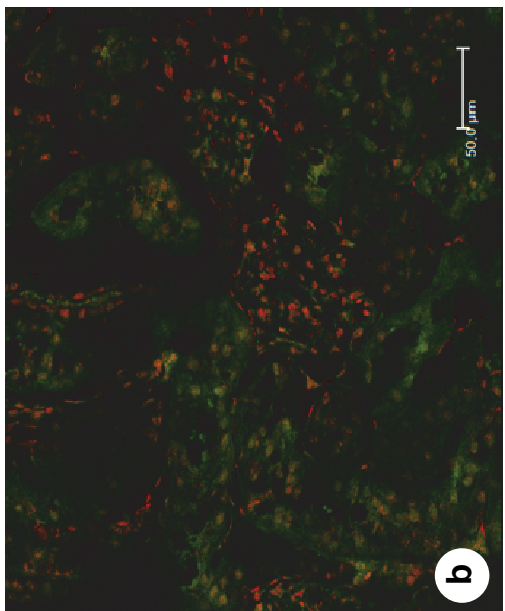

a

牙

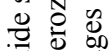

.. .

青管

$>^{\circ} . \Xi$

일

象定

要

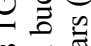

告家 0

$(0$
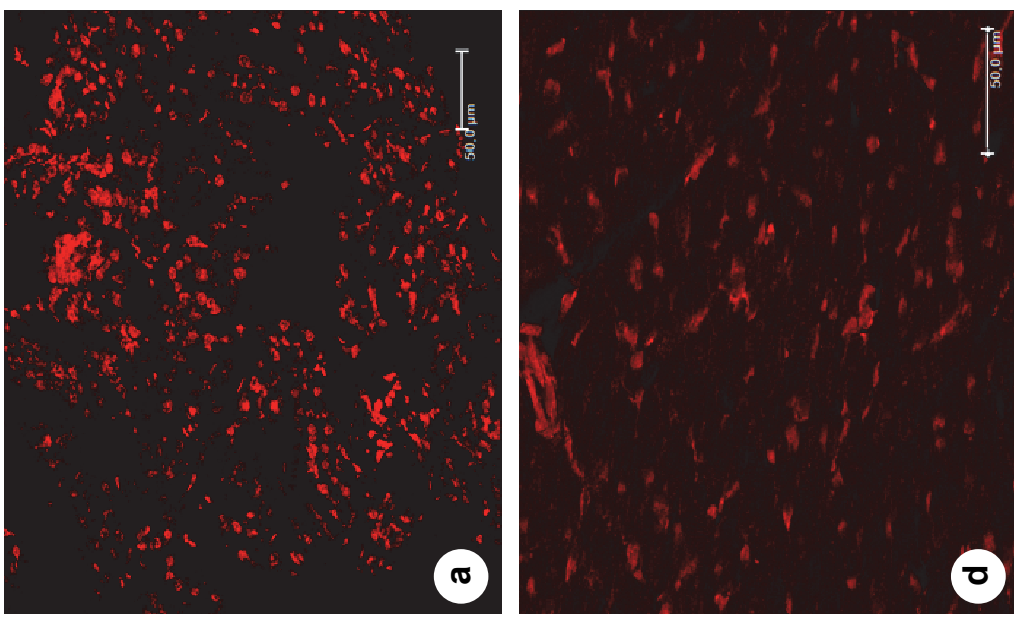

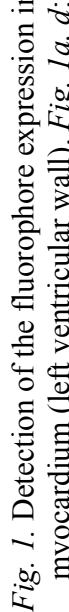



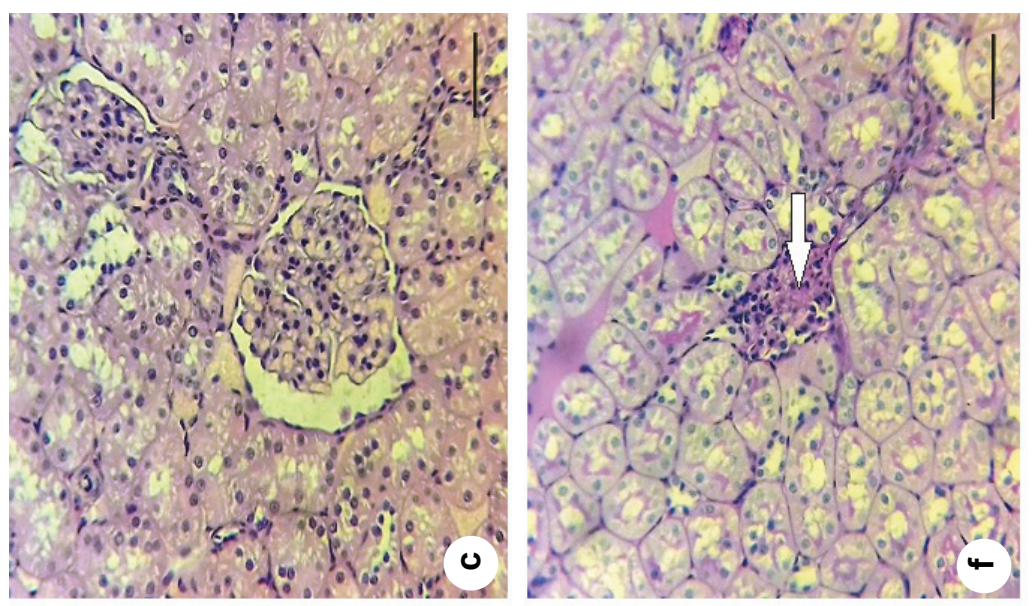

这

굴

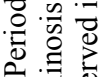

宁胥。

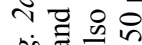

这.

of 0

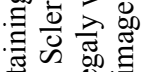

के $\dot{\sigma}:$

㺼实高

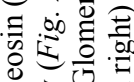

范
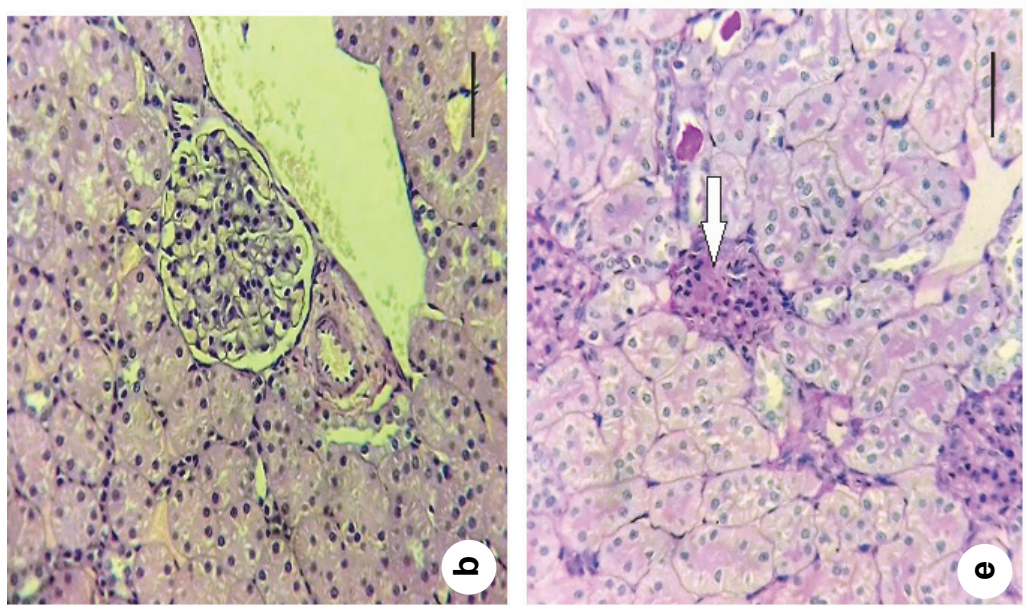

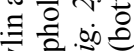

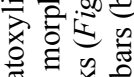

뜰 흥

过

ن च

ป⿻⺀大丶

so क त

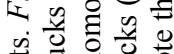

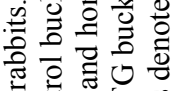

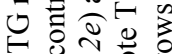

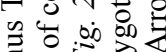

司这

$\therefore$ 응
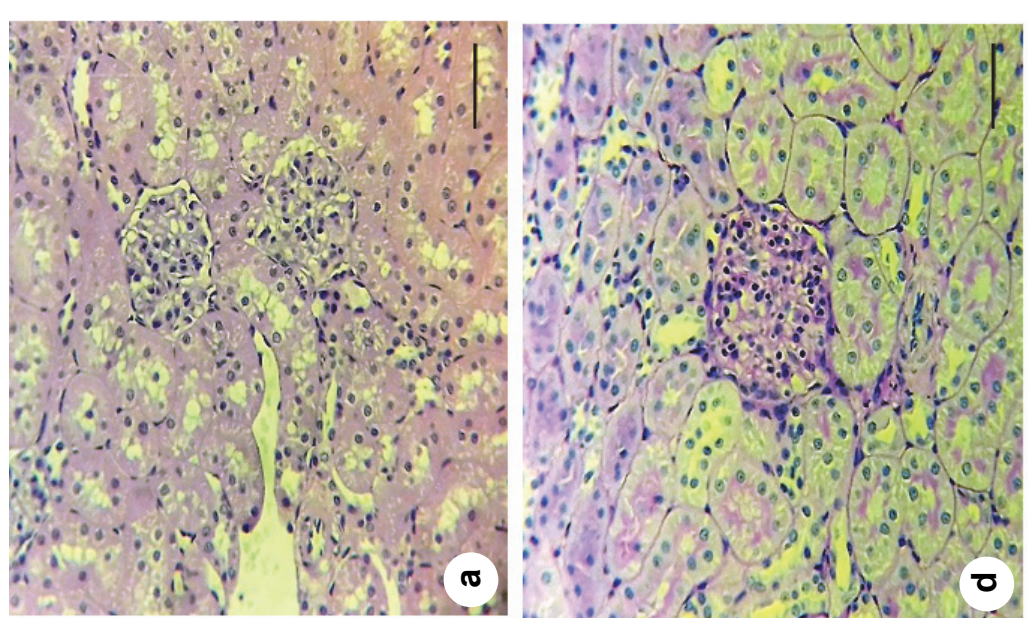

政

है F

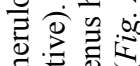

政这

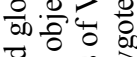

चำ

.

을

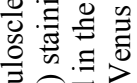

可家

恼

过

$\infty 0^{\circ}$ 

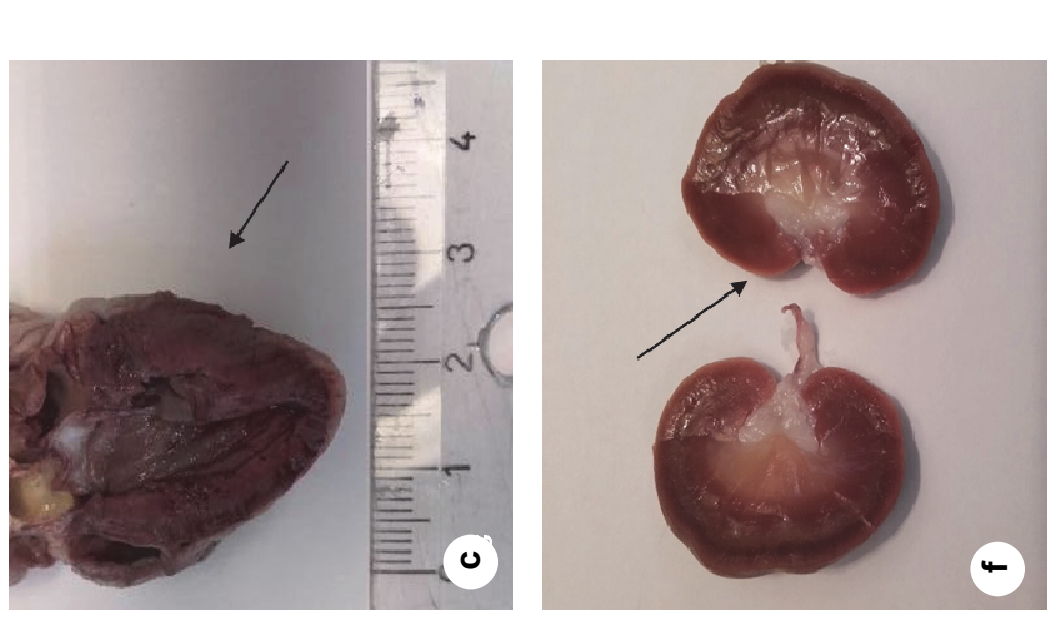

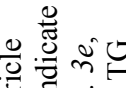

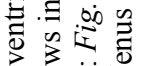
过 चे 范苛 区.

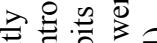
릉 के

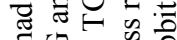
记 卷

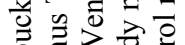

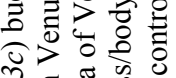
os $\frac{\text { a }}{3} \overline{3}$
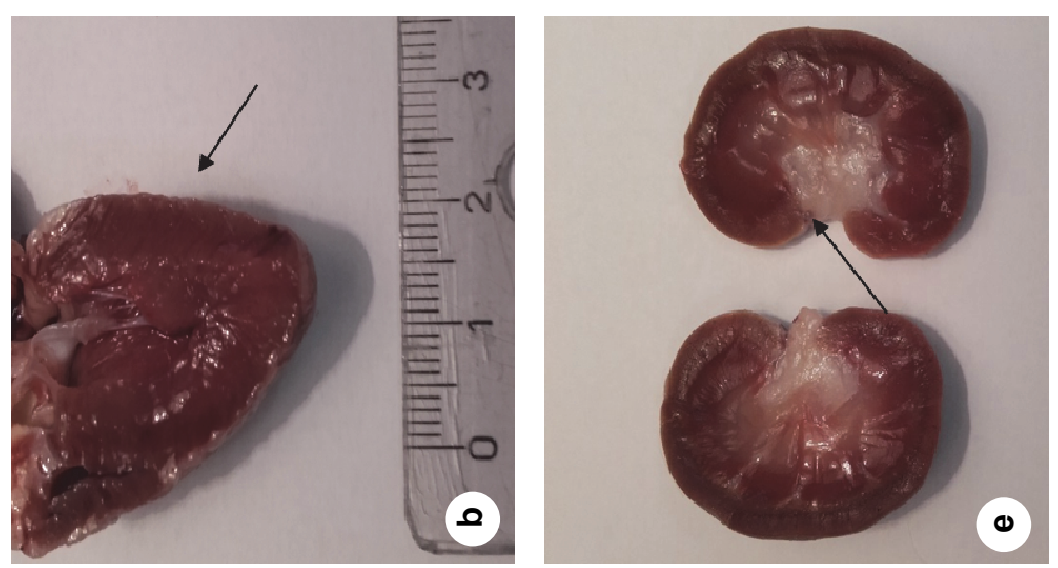

政

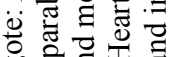

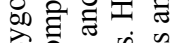

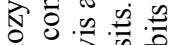

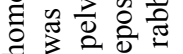

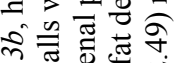
, 尔

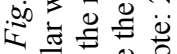

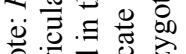
을

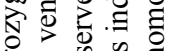

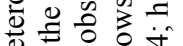
武势 O 击
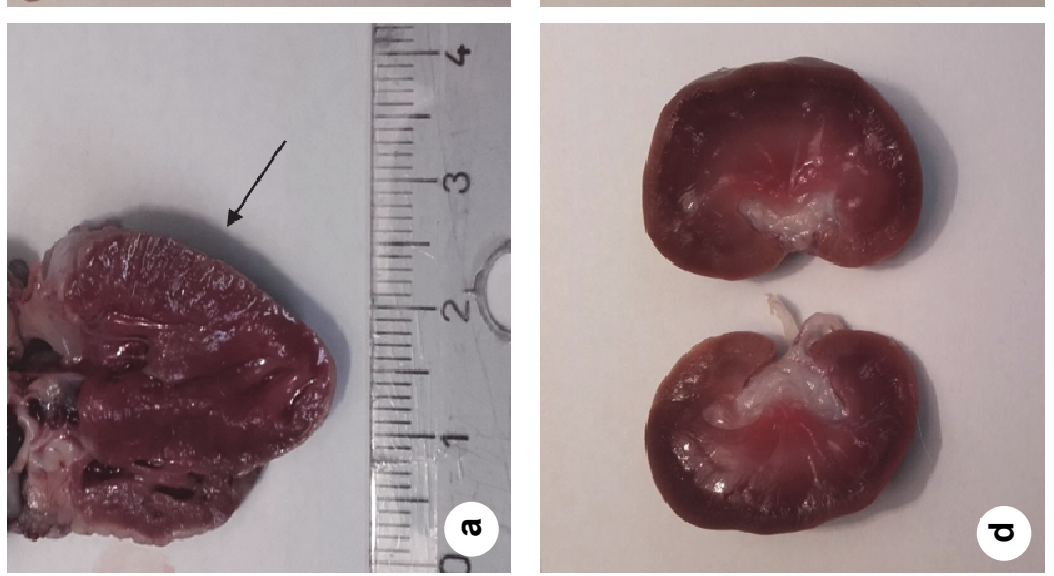

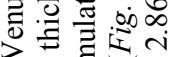
的言 呇和 b

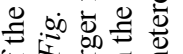
농 는

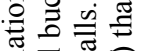
零命 है 券完 记

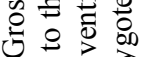
군 的总 造 这密焉 
Proteinuria and/or haematuria as the main signs of FSGS were detected in Venus heterozygote TG and homozygote bucks, respectively (Table 1). Our TP $(\mathrm{g} / \mathrm{L})$ data of the control group are comparable with the previously published normal values of 18 weeks old NZW rabbits $[0.33 \pm 0.13 \mathrm{~g} / \mathrm{L}$ (Tendron-Franzin et al., 2004)]. In the previous study using EGFP TG mice (3 to 29 weeks old), $40 \%$ of the examined TG mice had elevated urinary albumin level, but contrary to Venus TG rabbits, this TG mouse strain was not haematuric (Guo et al., 2007).

Robust fluorophore expression in the renal cortex of Venus heterozygote and homozygote TG rabbits was determined by confocal microscopy (Fig. 1. a-c) and microplate reader (Table 2). Sclerotic lesions, hyalinosis and glomerulomegaly were observed in the sections of Venus TG bucks of both genotypes (Fig. $2 \mathrm{~b}-\mathrm{c}$ and Fig. 2e-f, Table 3). In harmony with the data about glomerulosclerosis in CAGGS-EGFP mice (Guo et al., 2007), the overexpression of the fluorophore in the glomeruli was associated with the presence of FSGS in Venus TG bucks. This similarity suggests that this type of glomerulopathy might be a common problem in TG animals with ubiquitous GFP expression.

Table 3

Glomerular histology

\begin{tabular}{lccc}
\hline Groups & $\begin{array}{c}\text { Non-TG control } \\
(\mathrm{n}=6)\end{array}$ & $\begin{array}{c}\text { Venus TG } \\
\text { heterozygote } \\
(\mathrm{n}=6)\end{array}$ & $\begin{array}{c}\text { Venus TG } \\
\text { homozygote } \\
(\mathrm{n}=5)\end{array}$ \\
\hline $\begin{array}{l}\text { Sclerotic glomeruli/ } \\
50 \text { glomeruli ratio (PAS) }\end{array}$ & $2.33 \pm 1.51$ & $11.00 \pm 3.74^{*}$ & $10.00 \pm 7.07^{*}$ \\
\hline Glomerulomegaly (HE) & not detected & in 4 bucks & in 4 bucks
\end{tabular}

PAS: Periodic acid-Schiff (PAS); HE: haematoxylin and eosin. Asterisks denote significant differences. $\mathrm{F}_{(2.14)}=6.58, \mathrm{P}=0.01$ Venus TG heterozygote vs. control bucks and $\mathrm{P}=0.046$ Venus homozygote TG compared to control bucks

Glomerulomegaly is an enlargement of the glomeruli which could be caused by glomerular hypertrophy, hypertension and/or congenital oligomeganephronia (Fogo, 2015). Besides mild proteinuria, glomerulomegaly is early indicator of minimal change disease and FSGS (Fogo et al., 1990). Glomerulomegaly typically presents in the perihilar histological subtype of FSGS, which is an adaptive form of the disease in human patients (D'Agati et al., 2011).

In a previous report, TG mice with cardiac-specific GFP expression had dilated cardiomyopathy (Huang et al., 2000). Venus TG rabbits did not develop all histological and morphological findings of dilated cardiomyopathy (Fig. 3a-c); thus, the lower fluorophore expression in the myocardium of Venus TG rabbits (Fig. 1d-f) compared to the GFP TG mice (Huang et al., 2000) may not be strong enough to provoke all signs of this cardiac disease. 
The fat accumulation in the renal pelvis and renal medulla was more extensive in Venus TG rabbits than in the control (Fig. 3d-f).

In summary, Venus $\mathrm{TG}$ bucks had mild proteinuria and/or microscopic haematuria and FSGS with normal complete blood count. Our data indicated that the appearance of glomerulosclerosis in TG animals expressing the reporter GFP or its variants (EGFP, Venus) is not limited to mice.

\section{Acknowledgements}

This work was supported by the National Research, Development and Innovation Office (NKFIH) grant no. 108921, NVKP_16-1-2016-0039 to Z.B. and 120870 to N.L. L.H. and Z.B. are members of EU COST Action BM1308 Sharing Advances on Large Animal Models (SALAAM). The authors wish to thank the veterinary pathologists of the University of Veterinary Medicine (Budapest, Hungary), Valéria Dékay (Department of Clinical Pathology) and Gyula Balka (Department of Pathology) for the histological analysis and light microscopic imaging.

\section{References}

Adedoyin, O., Frank, R., Vento, S., Vergara, M., Gauthier, B. and Trachtman, H. (2004): Cardiac disease in children with primary glomerular disorders - role of focal segmental glomerulosclerosis. Pediatr. Nephrol. 19, 408-412.

Churg, J., Habib, R. and White, R. H. (1970): Pathology of the nephrotic syndrome in children: a report for the International Study of Kidney Disease in Children. Lancet 760, 1299-1302.

D'Agati, V. D., Kaskel, F. J. and Falk, R. J. (2011): Focal segmental glomerulosclerosis. N. Engl. J. Med. 365, 2398-2411.

Fogo, A. B. (2015): Causes and pathogenesis of focal segmental glomerulosclerosis. Nat. Rev. Nephrol. 11, 76-87.

Fogo, A., Hawkins, E. P., Berry, P. L., Glick, A. D., Chiang, M. L., MacDonell, R. C. Jr. and Ichikawa, I. (1990): Glomerular hypertrophy in minimal change disease predicts subsequent progression to focal glomerular sclerosis. Kidney Int. 38, 115-123.

Garrels, W., Mates, L., Holler, S., Dalda, A., Taylor, U., Petersen, B., Niemann, H., Izsvak, Z., Ivics, Z. and Kues, W. A. (2011): Germline transgenic pigs by Sleeping Beauty transposition in porcine zygotes and targeted integration in the pig genome. PLoS One 6 (8), e23573.

Gava, F. N., Zacche, E., Ortiz, E. M. G., Champion, T., Bandarra, M. B., Vasconcelos, R. O., Barbosa, J. C. and Camacho, A. A. (2013): Doxorubicin induced dilated cardiomyopathy in a rabbit model: An update. Res. Vet. Sci. 94, 115-121.

Guo, J. K., Cheng, E. C., Wang, L., Swenson, E. S., Ardito, T. A., Kashgarian, M., Cantley, L. G. and Krause, D. S. (2007): The commonly used beta-actin-GFP transgenic mouse strain develops a distinct type of glomerulosclerosis. Transgenic Res. 16, 829-834.

Hinton, M. (1981): Kidney disease in the rabbit - A histological survey. Lab. Anim. 15, 263-265.

Hocher, B., Thone-Reineke, C., Rohmeiss, P., Schmager, F., Slowinski, T., Burst, V., Siegmund, F., Quertermous, T., Bauer, C., Neumayer, H. H., Schleuning, W. D. and Theuring, F. (1997): Endothelin-1 transgenic mice develop glomerulosclerosis, interstitial fibrosis, and renal cysts but not hypertension. J. Clin. Invest. 99, 1380-1389. 
Huang, W. Y., Aramburu, J., Douglas, P. S. and Izumo, S. (2000): Transgenic expression of green fluorescence protein can cause dilated cardiomyopathy. Nat. Med. 6, 482-483.

Jenkins, J. R. (2008): Rabbit diagnostic testing. J. Exot. Pet Med. 17, 4-15.

Katter, K., Geurts, A. M., Hoffmann, O., Mates, L., Landa, V., Hiripi, L., Moreno, C., Lazar, J., Bashir, S., Zidek, V., Popova, E., Jerchow, B., Becker, K., Devaraj, A., Walter, I., Grzybowski, M., Corbett, M., Rangel, A., Hodges, M. R., Bader, M., Ivics, Z., Jacob, H. J., Pravenec, M., Bosze, Z., Rulicke, T. and Izsvak, Z. (2013): Transposon-mediated transgenesis, transgenic rescue, and tissue-specific gene expression in rodents and rabbits. FASEB J. 27, 930-941.

Khan, T. M. and Khan, K. N. M. (2015): Acute kidney injury and chronic kidney disease. Vet. Pathol. 52, 441-444.

Kimura, K., Tojo, A., Matsuoka, H. and Sugimoto, T. (1991): Renal arteriolar diameters in spontaneously hypertensive rats - vascular cast study. Hypertension 18, 101-110.

Kummer, S., von Gersdorff, G., Kemper, M. J. and Oh, J. (2012): The influence of gender and sexual hormones on incidence and outcome of chronic kidney disease. Pediatr. Nephrol. 27, 1213-1219.

Liptak, N., Hoffmann, O. I., Kerekes, A., Iski, G., Ernszt, D., Kvell, K., Hiripi, L. and Bosze, Z. (2017): Monitoring of Venus transgenic cell migration during pregnancy in non-transgenic rabbits. Transgenic Res. 26, 291-299.

Matsuo, S., Fukatsu, A., Taub, M. L., Caldwell, P. R., Brentjens, J. R. and Andres, G. (1987): Glomerulonephritis induced in the rabbit by antiendothelial antibodies. J. Clin. Invest. 79, $1798-1811$.

Melillo, A. (2007): Rabbit clinical pathology. J. Exot. Pet Med. 16, 135-145.

Michaud, J. L., Lemieux, L. I., Dube, M., Vanderhyden, B. C., Robertson, S. J. and Kennedy, C. R. J. (2003): Focal and segmental glomerulosclerosis in mice with podocyte-specific expression of mutant alpha-actinin-4. J. Am. Soc. Nephrol. 14, 1200-1211.

Okuyama, S., Hamai, K., Fujishima, M., Ohtani, H., Komatsuda, A., Sawada, K. and Wakui, H. (2007): Focal segmental glomerulosclerosis associated with polycythemia vera: report of a case and review of the literature. Clin. Nephrol. 68, 412-415.

Shimomura, O., Johnson, F. H. and Saiga, Y. (1962): Extraction, purification and properties of aequorin, a bioluminescent protein from the luminous hydromedusan, Aequorea. J. Cell. Comp. Physiol. 59, 223-239.

Takagi-Akiba, M., Asanuma, K., Tanida, I., Tada, N., Oliva Trejo, J. A., Nonaka, K., Asanuma, E., Kominami, E., Ueno, T. and Tomino, Y. (2012): Doxorubicin-induced glomerulosclerosis with proteinuria in GFP-GABARAP transgenic mice. Am. J. Physiol. Renal Physiol. 302, F380-389.

Takahashi, R., Kuramochi, T., Aoyagi, K., Hashimoto, S., Miyoshi, I., Kasai, N., Hakamata, Y., Kobayashi, E. and Ueda, M. (2007): Establishment and characterization of CAG/EGFP transgenic rabbit line. Transgenic Res. 16, 115-120.

Tendron-Franzin, A., Gouyon, J. B., Guignard, J. P., Decramer, S., Justrabo, E., Gilbert, T. and Semama, D. S. (2004): Long-term effects of in utero exposure to cyclosporin A on renal function in the rabbit. J. Am. Soc. Nephrol. 15, 2687-2693. 